\title{
Glucocorticoid hypersensitivity in an asthmatic patient: presentation and treatment
}

\author{
MD CLEE, J FERGUSON, MARGARET CK BROWNING, RT JUNG, RA CLARK \\ From the Department of Respiratory Medicine, King's Cross Hospital, and the Departments of Dermatology, \\ Biochemical Medicine, and Medicine, Ninewells Hospital and Medical School, Dundee
}

\begin{abstract}
Anaphylactoid reactions to oral, topical, and parenteral corticosteroids have been reported. ${ }^{1-s}$ This may present serious problems in management should steroid treatment be required. We describe a patient who showed an anaphylactoid reaction to several different corticosteroid preparations and was successfully desensitised to hydrocortisone.
\end{abstract}

\section{Case report}

A 31 year old woman with a history of urticaria and chest tightness precipitated by salicylate ingestion was admitted in 1972 with an acute attack of asthma $\left(F_{1} V_{1} 1.051\right)$. On discharge she was having prophylactic treatment that included $7.5 \mathrm{mg}$ prednisolone daily, (FEV, 1.65 l). Six months later she developed an urticarial eruption over the upper face; she had ingested no salicylates. Beclomethasone dipropionate by inhalation was introduced and the oral prednisolone reduced to $2.5 \mathrm{mg}$ daily; the rash subsided. The patient remained well with $2.5 \mathrm{mg}$ prednisolone daily for six years $\left(F E V_{1} 1.50-1.901\right)$, but after worsening of her asthma (FEV, $0.75 \mathrm{l})$ the dose of oral prednisolone was increased to $7.5 \mathrm{mg}$ daily and there was a recurrence of urticaria over the face and trunk associated with truncal and limb purpura. Investigations including platelet count, Hess test, clotting factor assays, and tests for platelet adhesion and aggregation with collagen and ADP showed no abnormality. The prednisolone was withdrawn and tetracosactrin depot $1 \mathrm{mg}$ intramuscularly twice weekly was introduced. Initially basal plasma cortisol concentrations were low $(<50 \mathrm{nmol} /)$ and rose little in response to tetracosactrin. About six weeks after the introduction of tetracosactrin depot, although the morning cortisol concentration remained low, the response had improved-a cortisol concentration of $1175 \mathrm{nmol} / \mathrm{l}$ being achieved. Initially the urticaria and purpura subsided, but after three months it was noted that the rash recurred within 24 hours of administration of tetracosactrin, subsiding again over the following 48 hours. During two weeks while on holiday the patient received no tetracosactrin and remained well and free of rash during this period. Twenty four hours after receiving a further injection of tetracosactrin she developed right iliac fossa pain and an extensive pruritic papular eruption over the face, limbs, and buttocks. Tetracosactrin treatment was withdrawn and, as she

Address for correspondence: Dr MD Clee, Stonehouse Hospital, Stonehouse, Lanarkshire.

Accepted 10 December 1984 would not comply in taking steroid by inhalation, attempts were made to treat her with non-steroidal antiasthmatic drugs. Her condition deteriorated (FEV, $0.80 \mathrm{l})$ and for the first time she was treated with $200 \mathrm{mg}$ hydrocortisone succinate given intravenously. Within four hours she developed right iliac fossa pain, melaena, and purpura over limbs, buttocks, and trunk, which regressed in 72 hours after treatment with both oral and intravenous chlorpheniramine maleate. A provisional diagnosis of an anaphylaxis like reaction to hydrocortisone was made and all steroid treatment was withheld. She did not, however, become acutely dyspnoeic during this episode. Chlorpheniramine was withdrawn and intradermal prick testing with various synthetic glucocorticoid preparations was performed. The most severe response was elicited 30 minutes after testing with hydrocortisone. Deflazacort, a new synthetic glucocorticoid, elicited a similar response despite

Results of intradermal testing of commercial and excipient free preparations of corticosteroids

\begin{tabular}{|c|c|c|}
\hline Agent tested & $\begin{array}{l}\text { Before desens- } \\
\text { itisation* }\end{array}$ & $\begin{array}{l}\text { After desens- } \\
\text { itisation }\end{array}$ \\
\hline $\begin{array}{l}\text { Dexamethasone (Oradexon, } \\
\text { Organon) } 4 \mathrm{mg} / \mathrm{ml} \\
\text { Dexamethasone excipient free } \\
0.1 \mathrm{mg} / \mathrm{ml} \\
\text { Dexamethasone excipient free } \\
0.01 \mathrm{mg} / \mathrm{ml} \\
\text { Control }\end{array}$ & $\begin{array}{l}++ \\
++ \\
++ \\
0\end{array}$ & $\begin{array}{l}0 \\
0 \\
0 \\
0\end{array}$ \\
\hline $\begin{array}{l}\text { Prednisolone (Codelsol, MSO) } \\
16 \mathrm{mg} / \mathrm{ml} \\
\text { Prednisolone excipient free } \\
0.5 \mathrm{mg} / \mathrm{ml} \\
\text { Prednisolone excipient free } \\
0.05 \mathrm{mg} / \mathrm{ml} \\
\text { Control }\end{array}$ & $\begin{array}{l}++ \\
++U \\
++U \\
0\end{array}$ & $\begin{array}{l}0 \\
0 \\
0 \\
0\end{array}$ \\
\hline $\begin{array}{l}\text { Hydrocortisone (Efcortesol, Glaxo) } \\
100 \mathrm{mg} / \mathrm{ml} \\
\text { Hydrocortisone excipient free } \\
0.25 \mathrm{mg} / \mathrm{ml} \\
\text { Hydrocortisone excipient free } \\
0.025 \mathrm{mg} / \mathrm{ml} \\
\text { Control }\end{array}$ & $\begin{array}{l}++++U \\
+++U \\
+++U \\
0\end{array}$ & $\begin{array}{l}0 \\
0 \\
0 \\
0\end{array}$ \\
\hline $\begin{array}{l}\text { Deflazacort excipient free } 0.1 \mathrm{mg} / \mathrm{ml} \\
\text { Deflazacort excipient free } 0.01 \mathrm{mg} / \mathrm{ml} \\
\text { Control }\end{array}$ & $\begin{array}{l}++\mathrm{U} \\
++ \\
0\end{array}$ & $\begin{array}{l}\mathbf{0} \\
\mathbf{0} \\
\mathbf{0}\end{array}$ \\
\hline Distilled water control & 0 & $\mathbf{0}$ \\
\hline
\end{tabular}


having a very different structure from the other compounds tested (table). Intradermal scratch and distilled water controls produced no reactions, excluding both dermographism and aquagenic urticaria. In three normal subjects identical testing gave negative results. Immunofluorescence studies on a punch biopsy specimen of skin giving a positive reaction to an intradermal test for hydrocortisone failed to show antibody-antigen complexes, nor could specific antibodies to hydrocortisone be detected in venous blood. Circulating levels of immunoglobulins within reference limits (IgG 10.2, $\operatorname{IgA} 2.66$, and $\operatorname{IgM}$ $2.33 \mathrm{~g} / \mathrm{l}$ and $\mathrm{IgE} 50 \mathrm{U} / \mathrm{l})$.

In the absence of steroid treatment the patient's asthma deteriorated (peak flow $60 \mathrm{lmin}^{-1}$ ) and it was decided to attempt desensitisation to glucocorticoids in the hope that these could once again be used to control the asthma. Oral hydrocortisone in the following doses, gradually increasing from day 1 to day 30 , was used: day $1-15 \mu \mathrm{g} ; 2-30 \mu \mathrm{g}$; 3-60 $\mu \mathrm{g} ; 4-120 \mu \mathrm{g} ; 5-11-150 \mu \mathrm{g} ; 12-300 \mu \mathrm{g} ; 13-$ $600 \mu \mathrm{g} ; 14-1.2 \mathrm{mg} ; 15-21-1.5 \mathrm{mg} ; 22-3 \mathrm{mg} ; 23-$ $6 \mathrm{mg} ; 24-12 \mathrm{mg} ; 25-27-15 \mathrm{mg} ; 28-30-20 \mathrm{mg} ; 31-$ 46 - dose increased by $5 \mathrm{mg} /$ day to maximum of $100 \mathrm{mg}$.

At the end of the desensitisation programme the patient was challenged with an intravenous injection of $100 \mathrm{mg}$ hydrocortisone succinate. No adverse reaction occurred. Testing with the several steroid agents previously capable of provoking erythema and urticaria was repeated and gave negative results (table).

After desensitisation the IgG concentration showed a slight rise (to $13.0 \mathrm{~g} / \mathrm{l}$ ), $\operatorname{IgA}, \operatorname{IgM}$, and $\operatorname{IgE}$ remaining unchanged. The patient has remained stable with a maintenance oral dose of $\mathbf{4 0} \mathrm{mg}$ hydrocortisone daily, with no evidence of urticaria and an FEV, of 1.25-1.40 1.

\section{Discussion}

The patient reported here developed hypersensitivity reactions to several corticosteroid preparations from both systemic administration and skin testing. The intradermal provocation tests showed that the reactions were caused by the steroids themselves rather than by additives, distilled water, or a physical scratch.

Prolonged treatment, even with relatively small doses of synthetic glucocorticoids, may cause adrenal atrophy and consequent impairment of the response to tetracosactrin. The initial lack of any adverse response to tetracosactrin reflects the poor rise in cortisol at this time. Recurrence of the rash in response to tetracosactrin administration occur- red at a time when adrenocortical function had been shown to have improved.

The mechanism of the hypersensitivity response remains unclear; we were unable to demonstrate an immunological basis. The patient showed an adverse response to the naturally occurring glucocorticoid hydrocortisone, to the structurally similar synthetic glucocorticoids prednisolone and dexamethasone, and to a third synthetic compound, deflazacort, which is structurally very different from hydrocortisone.

Since glucocorticoid treatment was considered essential for the management of this patient, desensitisation in a manner similar to that described for sulphasalazine ${ }^{6}$ was attempted and successfully achieved over a seven week period. Pleskow et al ${ }^{7}$ desensitised aspirin-sensitive asthmatic patients to aspirin but found that the desensitisation effect gradually disappeared over several days if aspirin was withheld. We have continued to treat the patient with hydrocortisone and cannot therefore comment on whether desensitisation would wane on withdrawal of the steroid. Those patients who develop an anaphylactic reaction to glucocorticoids are likely to have been treated in the past with these drugs and to have a clinical condition which may necessitate their use again in future management. We recommend that in such cases a desensitisation programme such as we described should be attempted. The mechanism of the hypersensitivity and desensitisation responses requires further study.

\section{References}

1 Mendelson LM, Meltzer EO, Hamburger RN. Anaphylaxislike reactions to corticosteroid therapy.J Allergy Clin Immunol 1974;54: 125-31.

2 Hayhurst M, Braude A, Benatar SR. Anaphylactic-like reaction to hydrocortisone. S Afr Med J 1978;53:259-60.

3 Kounis NG. Untoward reactions to corticosteroids: intolerance to hydrocortisone. Ann Allergy 1976;36:204-6.

4 Ashford RFU, Bailey A. Angioneurotic oedema and urticaria following hydrocortisone-a further case. Postgrad Med J 1980;56:437.

5 Partridge MR, Gibson GJ. Adverse bronchial reactions to intravenous hydrocortisone in two aspirin-sensitive asthmatic patients. Br Med J 1978;i: 1521-2.

6 Holdsworth CD. Sulphasalazine desensitisation. Br Med J 1981;282:110.

7 Pleskow WW, Stevenson DD, Mathison DA, et al. Aspirin desensitisation in aspirin-sensitive asthmatic patients. Clinical manifestations and characterisation of the refractory period. $J$ Allergy Clin Immunol 1982;69:11-19. 